\title{
Variable antibiotic susceptibility patterns among Streptomyces species causing actinomycetoma in man and animals
}

\author{
Mohamed E Hamid
}

\begin{abstract}
Background: Drug therapy is recommended in conjunction with surgery in treatment of actinomycetoma. The specific prescription depends on the type of bacteria (actinomycetoma) or fungi (eumycetoma) causing the disease and their in vitro antimicrobial susceptibility.

Objectives: To investigate the antimicrobial susceptibility among isolates of Streptomyces spp. isolated from cases of actinomycetoma in man and animals in Sudan.

Methods: Streptomyces strains $(n=18)$ isolated from cases of actinomycetoma were tested in vitro against 15 commonly prescribed antibacterial agents using MIC agar dilution method as per standard guidelines.

Results: Streptomyces strains isolated from actinomycetoma fall into various phenotypic groups. All of the strains were inhibited by novobiocin $(8 \mu \mathrm{g} / \mathrm{mL})$, gentamycin $(8,32 \mu \mathrm{g} / \mathrm{mL})$ and doxycycline $(32 \mu \mathrm{g} / \mathrm{mL})$. Fusidic acid $(64 \mu \mathrm{g} / \mathrm{mL})$ inhibited $94.4 \%$ of the strains; bacitracin, streptomycin, cephaloridine, clindamycin, ampicillin, rifampicin and tetracycline $(64 \mu \mathrm{g} / \mathrm{mL})$ inhibited between 61.1 and $77.8 \%$ of the strains. All strains were found resistant to amphotericin B $(64 \mu \mathrm{g} / \mathrm{mL})$, penicillin $(20 \mu \mathrm{g} / \mathrm{mL})$ and sulphamethoxazole $(64 \mu \mathrm{g} / \mathrm{mL})$.

Conclusions: Saprophytic Streptomyces spp. cause actinomycetoma in man and animal belong to separate phenotypes and have a wide range of susceptibility patterns to antimicrobial agents, which pose a lot of difficulties in selecting effective in vivo treatment for actinomycetoma.
\end{abstract}

Keywords: Antibiotic susceptibility, Streptomyces, Actinomycetoma, Sudan

\section{Background}

Actinomycetoma is a slowly progressive, destructive infection of the cutaneous and subcutaneous tissues, fascia, and bones, caused by fungi (eumycetoma) or by aerobic actinomycete bacteria (actinomycetoma or actinomycotic mycetoma) and mainly prevalent in tropical countries [1]. The major agents of aerobic actinomycetes are: Nocardia brasiliensis, Actinomadura madurae and Streptomyces somaliensis [2,3]. Strep. sudanensis has recently being described as one of the etiological agents of actinomycetoma [4]. Actinomycetoma is a major health problem in parts of Sudan [5-8].

Diagnosis of mycetoma relies on direct examination of grains and isolation of the etiologic agents. The discharging

Correspondence: mehamid2@yahoo.com

Department of Microbiology, College of Medicine, King Khalid University, P. O. Box 641, Abha, Kingdom of Saudi Arabia grains represent aggregates of bacterial filaments or fungal hyphae. The salient features of the grains may assist in the clinical diagnosis: eumycetomas due to Madurella spp. typically produce black grains; actinomycetomas never produce dark grains, and usually are yellow to orange; and those caused by Actinomadurae pelletieri are red to pink $[3,7,9]$. Analysis of mycetoma sampled for further histological processing provides some clues to the potential microorganism, but culture is the gold standard for diagnosis [10].

It seems likely that patients who do not respond to standard therapeutic treatment may be infected with unknown actinomycetes and thereby requires specific antibiotic treatment regimes [11]. This is a serious problem as actinomycetoma becomes dangerous to health, or even life, when treatment is inadequate or delayed. A thorough microbiological diagnosis while desirable is

\section{() Biomed Central}


not always possible due to difficulties in isolating and characterizing the causal agents.

The aim of this study was to investigate the susceptibility of various phenotypes of streptomycetes isolated from cases of actinomycetoma in human (madura foot) and donkeys (fistulus wihters) in Sudan.

\section{Materials and methods}

\section{Strains}

The present study perform antimicrobial sensitivity testing on Streptomyces strains $(\mathrm{n}=18)$ isolated from cases of actinomycetoma in human (madura foot) and actinomycetoma in donkeys (fistulus wihters) between 1998 and 2003 in Khartoum State, Sudan. The 18 Streptomyces strains are labeled as SD551, SD552, SD559, SD572, SD573, SD575, SD576 (donkey isolates) and S. somaliensis DSM $40738^{\mathrm{T}}$, S. sudanensis DSM 41923 ${ }^{\mathrm{T}}$, SD509, DSM41607, DSM41608, DSM41609, Streptomyces spp.: SD511, SD524, SD528, SD534 and DSM40760 (human isolates).

S. somaliensis DSM $40738^{\mathrm{T}}$ and S. sudanensis DSM $41923^{\mathrm{T}}$ served as controls. Details of strains and isolation methods have been described previously $[4,12]$. The strains were sub cultured from frozen $20 \%$ glycerol stocks on Tryptic Soy agar plates (TSA; Difco). The inoculated plates were incubated aerobically at $37^{\circ} \mathrm{C}$ for up to seven days.

\section{Identification scheme}

Isolates were tentatively identified as member of the genus Streptomyces on the basis of selected phenotypic criteria [13]. The cultural and microscopic features of the genus Streptomyces are: aerobic growth, gram-positive, non-acid-alcohol-fast, non-motile actinomycete which forms extensively branched, light yellow substrate mycelia on a variety of media with or without aerial hyphae, with or without diffusible pigments on the media. In the present study phenotypic clusters of isolates were identified mainly on colony color and presence of diffusible pigments (Figure 1).

\section{Antimicrobial Susceptibility Tests}

Streptomyces isolates $(\mathrm{n}=18)$ including clinical isolates and type strains of S. somaliensis DSM $40738^{\mathrm{T}}$, S. sudanensis DSM $41923^{\mathrm{T}}$ (Table 1) were tested for their ability to grow in TSA supplemented with antibiotics or antimicrobial agents using the minimum inhibitory concentration (MIC) agar dilution method. These were performed according to standard methods [14]. A homogeneous bacterial suspension giving an inoculum of $10^{6}-10^{8} \mathrm{CFU} / \mathrm{mL}$ was prepared by dissolving 1-3 colonies in sterile $2 \mathrm{~mL}$ normal saline. The suspension was used to inoculate each TSA plates containing the antimicrobial agents and control plates (without drugs) using a Steer's replicator.
A total of 15 antimicrobial agents (Table 1) in twofold to threefold dilution series from 4 to $64 \mu \mathrm{g} / \mathrm{mL}$ making up a total of 25 concentrations were used. The range is within the values recommended by the NCCLS [14]. The test and control agar plates were incubated aerobically at $30^{\circ} \mathrm{C}$, for $48-72 \mathrm{~h}$. After incubation, the organisms were classified as sensitive (S) or resistant (R) according to guidelines [14].

\section{Results}

The identification of isolates to cluster and phenotypic groups was done according to microscopic and growth characteristics. The isolates exhibited different phenotypic features (Figure 1). Figure 1 showed examples of colony morphology variations which ranged from grey to blue to grey brown or grey white colonies. The full identification of the isolates is under studies to establish their taxonomic positions.

The results of antimicrobial susceptibility testing are shown in Table 1 and Figure 2. Three agents: novobiocin $(8 \mu \mathrm{g} / \mathrm{mL})$, gentamycin sulphate $(8,32 \mu \mathrm{g} / \mathrm{mL})$ and doxycycline hydrochloride $(32 \mu \mathrm{g} / \mathrm{mL})$ inhibited all strains. Fusidic acid $(64 \mu \mathrm{g} / \mathrm{mL})$ inhibited $94.4 \%$ of the strains; bacitracin $(16 \mu \mathrm{g} / \mathrm{mL})$ inhibited $77.8 \%$ of the strains; streptomycin sulphate $(8 \mu \mathrm{g} / \mathrm{mL})$ and cephaloridine $\mathrm{HCl}(32 \mu \mathrm{g} / \mathrm{mL})$ inhibited $66.7 \%$ of the strains; clindamycin $\mathrm{HCl}(8 \mu \mathrm{g} / \mathrm{mL})$; ampicillin $\mathrm{HCl}(32 \mu \mathrm{g} / \mathrm{mL})$; rifampicin $(32 \mu \mathrm{g} / \mathrm{mL})$ and tetracycline $\mathrm{HCl}(64 \mu \mathrm{g} / \mathrm{mL})$ inhibited $61.1 \%$ of the strains.

Other antibacterial agents revealed results ranging from 0 to $85 \%$. All strains were found resistant to amphotericin B $(64 \mu \mathrm{g} / \mathrm{mL})$, penicillin $(20 \mu \mathrm{g} / \mathrm{mL})$ and sulphamethoxazole $(64 \mu \mathrm{g} / \mathrm{mL})$ (Table 1; Figure 2).

\section{Discussion}

Regular surveillance of hospital-associated actinomycetoma infections and monitoring of antibiotic sensitivity pattern is required to prompt the treatment alone or in conjunction with surgery to reduce chance of amputation and prolong patient hospitalization due to actinomycetoma. Uses of antibiotic sensitivity testing helps to guide physicians in choosing antibiotics, but our findings indicated that large, seemingly unlimited numbers of saprophytic Streptomyces, potentially new species, exhibited various antimicrobial profiles. In the present study 13 phenotypic groups become apparent out of 18 clinical isolates and showed 15 different antibacterial susceptibility profiles. The accumulated sensitivity results on different pathogens guide physicians in choosing empirical treatment in serious patients before the individual's laboratory results are analyzed in the microbiology laboratory. In the present study four antibiotics (novobiocin, gentamycin, doxycycline and fusidic acid) inhibited more than $90 \%$ of the strains, which could be 


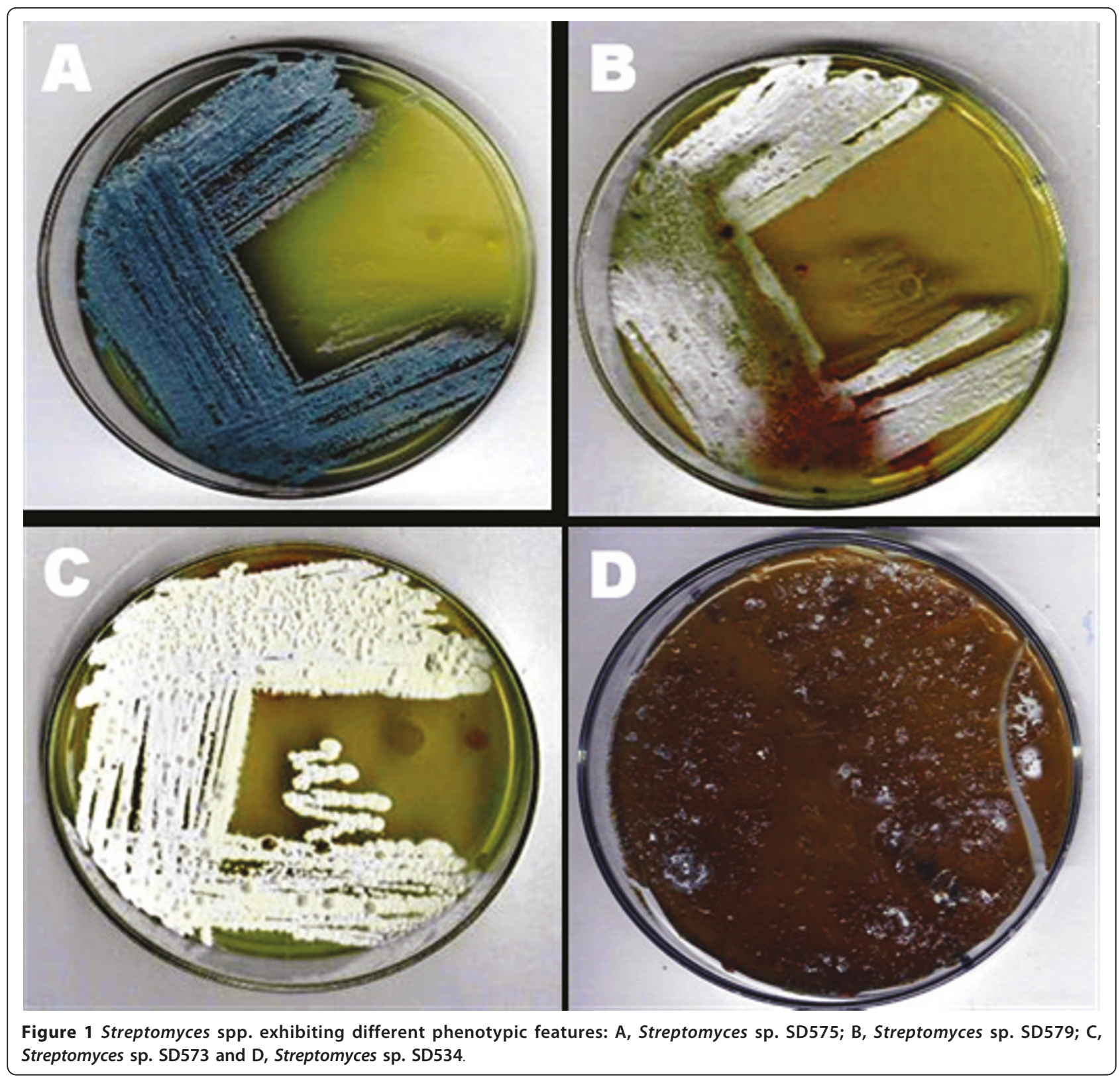

alone or in combination one of the choices in the treatment of actinomycetoma. Even though, a combination of sulphamethoxazole and trimethoprim is commonly used as treatment worldwide [15]. Currently the common drugs regimes practiced in Sudan for the treatment of actinomycetoma are amikacin in combination with co-trimoxazole and in resistant cases other drugs such as streptomycin combined with co-trimoxazole or streptomycin combined with rifampicin are practiced [16].

Nasher et al. [17] reported that rifampicin was the most effective antibiotic against $S$. somaliensis strains isolated from Sudanese patients, followed by erythromycin, tobramycin, fusidic acid and streptomycin sulphate.
In contrast they found that $S$. somaliensis strains were all resistant to trimethoprim. The present study emphasized that isolates from Sudanese patients are not all $S$. somaliensis, instead S. sudanensis, and other unidentified isolates are causal agents with different antimicrobial profiles. The two studies applied different methods and the species analyzed in Nasher et al. [17] study might have included strains other than $S$. somaliensis. Nevertheless, the findings in the present study found that the majority of the strains were sensitive to fusidic acid.

Kelly et al. [18] documented an excellent correlation when four methods for testing the antibacterial, including the agar dilution method which has been adopted in 
Table 1 The results of antimicrobial susceptibility of 18 strains of Streptomyces to 15 antimicrobial agents (25 total folds)

\begin{tabular}{|c|c|c|c|c|c|c|c|c|c|c|c|c|c|c|c|c|c|c|}
\hline $\begin{array}{l}\text { Strain* } \\
\text { Resistance to antimicrobial agents ( } \mu \mathrm{g} \mathrm{ml}-1) \text { : }\end{array}$ & 1 & 2 & 3 & 4 & 5 & 6 & 6 & 8 & 9 & 10 & 11 & 12 & 13 & 14 & 15 & 16 & 17 & 18 \\
\hline Amphotericin B (16) & $\mathrm{R}$ & $R$ & $\mathrm{R}$ & $R$ & $\mathrm{R}$ & $\mathrm{R}$ & $\mathrm{R}$ & $\mathrm{R}$ & $\mathrm{R}$ & $\mathrm{R}$ & $R$ & $\mathrm{R}$ & $\mathrm{R}$ & $\mathrm{R}$ & $R$ & $\mathrm{R}$ & $\mathrm{R}$ & $\mathrm{R}$ \\
\hline Amphotericin B (32) & $\mathrm{R}$ & $\mathrm{R}$ & $\mathrm{R}$ & $\mathrm{R}$ & $\mathrm{R}$ & $\mathrm{R}$ & $\mathrm{R}$ & $\mathrm{R}$ & $\mathrm{R}$ & $\mathrm{R}$ & $\mathrm{R}$ & $\mathrm{R}$ & $\mathrm{R}$ & $\mathrm{R}$ & $\mathrm{R}$ & $\mathrm{R}$ & $\mathrm{R}$ & $\mathrm{R}$ \\
\hline Amphotericin B (64) & $\mathrm{R}$ & $R$ & $\mathrm{R}$ & $\mathrm{R}$ & $\mathrm{R}$ & $\mathrm{R}$ & $\mathrm{R}$ & $R$ & $\mathrm{R}$ & $R$ & $R$ & $\mathrm{R}$ & $R$ & $R$ & $R$ & $\mathrm{R}$ & $\mathrm{R}$ & $\mathrm{R}$ \\
\hline Ampicillin hydrochloride (8) & $\mathrm{R}$ & $\mathrm{R}$ & $\mathrm{R}$ & $\mathrm{R}$ & $\mathrm{R}$ & $\mathrm{R}$ & $\mathrm{R}$ & $\mathrm{R}$ & $\mathrm{R}$ & $\mathrm{R}$ & $\mathrm{R}$ & $\mathrm{R}$ & $\mathrm{R}$ & $S$ & $\mathrm{R}$ & $S$ & $\mathrm{R}$ & $\mathrm{R}$ \\
\hline Ampicillin hydrochloride (32) & $\mathrm{R}$ & $\mathrm{R}$ & $\mathrm{R}$ & $\mathrm{R}$ & $S$ & $S$ & $\mathrm{R}$ & $S$ & $S$ & S & S & $\mathrm{s}$ & $S$ & $S$ & $\mathrm{R}$ & $S$ & $S$ & $\mathrm{R}$ \\
\hline Amoxicillin (32) & $\mathrm{R}$ & $\mathrm{R}$ & $\mathrm{R}$ & $\mathrm{R}$ & $\mathrm{R}$ & $S$ & $\mathrm{R}$ & $\mathrm{R}$ & $\mathrm{R}$ & $R$ & $\mathrm{R}$ & $\mathrm{R}$ & $\mathrm{R}$ & S & $R$ & $S$ & $\mathrm{R}$ & $\mathrm{R}$ \\
\hline Amoxicillin (64) & $\mathrm{R}$ & $\mathrm{R}$ & $\mathrm{R}$ & $\mathrm{R}$ & $\mathrm{R}$ & $\mathrm{R}$ & $\mathrm{R}$ & $\mathrm{R}$ & $\mathrm{R}$ & $\mathrm{R}$ & $\mathrm{R}$ & $R$ & $\mathrm{R}$ & $\mathrm{R}$ & $\mathrm{R}$ & $S$ & $\mathrm{R}$ & $\mathrm{R}$ \\
\hline Bacitracin (16) & $\mathrm{S}$ & $\mathrm{S}$ & $\mathrm{R}$ & $\mathrm{S}$ & $S$ & $S$ & $\mathrm{R}$ & $S$ & $S$ & $S$ & $S$ & $S$ & $S$ & $\mathrm{R}$ & $\mathrm{s}$ & $S$ & $S$ & $\mathrm{R}$ \\
\hline Cephaloridine hydrochloride (32) & $\mathrm{R}$ & $\mathrm{R}$ & $\mathrm{R}$ & $S$ & $S$ & $S$ & $\mathrm{R}$ & $S$ & $S$ & $S$ & $S$ & $S$ & $S$ & $S$ & $\mathrm{R}$ & $S$ & $S$ & $\mathrm{R}$ \\
\hline Clindamycin hydrochloride (8) & $\mathrm{R}$ & $\mathrm{R}$ & $\mathrm{R}$ & $\mathrm{R}$ & $\mathrm{S}$ & $S$ & $\mathrm{R}$ & $\mathrm{s}$ & $\mathrm{S}$ & $S$ & $\mathrm{~S}$ & $\mathrm{~S}$ & $S$ & $S$ & $\mathrm{R}$ & $\mathrm{S}$ & $S$ & $\mathrm{R}$ \\
\hline Doxycycline hydrochloride (16) & $\mathrm{S}$ & $\mathrm{R}$ & $\mathrm{R}$ & $S$ & $\mathrm{~S}$ & $S$ & $\mathrm{~s}$ & $\mathrm{~S}$ & $S$ & $S$ & $S$ & $S$ & $S$ & $S$ & $S$ & $S$ & $S$ & $\mathrm{R}$ \\
\hline Doxycycline hydrochloride (32) & s & $\mathrm{s}$ & $S$ & s & s & s & $S$ & $S$ & $S$ & $S$ & $S$ & $S$ & $S$ & $S$ & $S$ & $S$ & $S$ & $S$ \\
\hline Fusidic acid (32) & $S$ & $\mathrm{R}$ & $\mathrm{R}$ & $\mathrm{S}$ & $\mathrm{s}$ & $S$ & $\mathrm{R}$ & $\mathrm{S}$ & $\mathrm{S}$ & $S$ & $S$ & $S$ & $S$ & $S$ & $S$ & $S$ & $S$ & $\mathrm{~S}$ \\
\hline Fusidic acid (64) & s & $\mathrm{s}$ & $\mathrm{R}$ & s & s & s & $\mathrm{S}$ & $\mathrm{S}$ & $S$ & $S$ & $S$ & $S$ & $S$ & $S$ & $S$ & $S$ & $S$ & $S$ \\
\hline Gentamycin sulphate (8) & $S$ & $\mathrm{~S}$ & $\mathrm{~S}$ & $\mathrm{~S}$ & $\mathrm{~S}$ & $S$ & $\mathrm{R}$ & $\mathrm{S}$ & $S$ & $S$ & $S$ & $S$ & $S$ & $S$ & $S$ & $S$ & $S$ & $S$ \\
\hline Gentamycin sulphate (32) & s & $\mathrm{s}$ & $\mathrm{S}$ & s & s & s & $\mathrm{S}$ & $\mathrm{S}$ & $S$ & $S$ & $S$ & $S$ & $\mathrm{~s}$ & $S$ & $S$ & $S$ & $S$ & $S$ \\
\hline Novobiocin (4) & $\mathrm{s}$ & $\mathrm{R}$ & $\mathrm{R}$ & $\mathrm{S}$ & $S$ & $S$ & $\mathrm{~S}$ & $S$ & $S$ & $S$ & $S$ & $S$ & $S$ & $S$ & $S$ & S & $S$ & $\mathrm{~S}$ \\
\hline Novobiocin (8) & $\mathrm{s}$ & s & $S$ & s & s & s & $S$ & $S$ & $S$ & $S$ & $S$ & $S$ & $S$ & $S$ & $S$ & $S$ & $S$ & $S$ \\
\hline Rifampicin (32) & $\mathrm{R}$ & $\mathrm{R}$ & $\mathrm{R}$ & $\mathrm{S}$ & $S$ & $S$ & $\mathrm{R}$ & $\mathrm{S}$ & $S$ & $S$ & $S$ & $S$ & $S$ & $\mathrm{R}$ & $\mathrm{s}$ & $S$ & $R$ & $\mathrm{R}$ \\
\hline Penicillin G (10) & $\mathrm{R}$ & $\mathrm{R}$ & $\mathrm{R}$ & $R$ & $\mathrm{R}$ & $\mathrm{R}$ & $\mathrm{R}$ & $\mathrm{R}$ & $\mathrm{R}$ & $R$ & $\mathrm{R}$ & $\mathrm{R}$ & $\mathrm{R}$ & $\mathrm{R}$ & $\mathrm{R}$ & $\mathrm{R}$ & $\mathrm{R}$ & $\mathrm{R}$ \\
\hline Penicillin G (20) & $\mathrm{R}$ & $\mathrm{R}$ & $\mathrm{R}$ & $\mathrm{R}$ & $\mathrm{R}$ & $R$ & $\mathrm{R}$ & $\mathrm{R}$ & $R$ & $R$ & $\mathrm{R}$ & $\mathrm{R}$ & $R$ & $\mathrm{R}$ & $R$ & $\mathrm{R}$ & $\mathrm{R}$ & $\mathrm{R}$ \\
\hline Streptomycin sulphate (8) & $S$ & $R$ & $\mathrm{R}$ & $R$ & $S$ & $S$ & $S$ & $S$ & $S$ & $S$ & $S$ & $S$ & $S$ & $R$ & $R$ & $S$ & $S$ & $\mathrm{R}$ \\
\hline Sulphamethoxazole (32) & $\mathrm{R}$ & $\mathrm{R}$ & $\mathrm{R}$ & $\mathrm{R}$ & $\mathrm{R}$ & $\mathrm{R}$ & $R$ & $\mathrm{R}$ & $\mathrm{R}$ & $R$ & $\mathrm{R}$ & $R$ & $R$ & $R$ & $\mathrm{R}$ & $\mathrm{R}$ & $R$ & $\mathrm{R}$ \\
\hline sulphamethoxazole (64) & $\mathrm{R}$ & $\mathrm{R}$ & $\mathrm{R}$ & $\mathrm{R}$ & $\mathrm{R}$ & $\mathrm{R}$ & $\mathrm{R}$ & $\mathrm{R}$ & $\mathrm{R}$ & $R$ & $\mathrm{R}$ & $\mathrm{R}$ & $R$ & $R$ & $R$ & $\mathrm{~S}$ & $\mathrm{R}$ & $\mathrm{R}$ \\
\hline Tetracycline hydrochloride (64) & $\mathrm{R}$ & $R$ & $\mathrm{R}$ & $\mathrm{R}$ & $\mathrm{S}$ & $\mathrm{S}$ & $\mathrm{R}$ & $\mathrm{S}$ & $\mathrm{S}$ & $S$ & $\mathrm{~S}$ & $\mathrm{~S}$ & $R$ & $S$ & $\mathrm{~s}$ & S & $\mathrm{S}$ & $\mathrm{R}$ \\
\hline
\end{tabular}

Abbreviations: $S$, sensitive, $R$, resistant.

* Strains: 1, Streptomyces sp. SD551; 2, Streptomyces sp. SD552; 3, Streptomyces sp. SD559; 4, Streptomyces sp. SD572; 5, Streptomyces sp. SD573; 6, Streptomyces sp. SD575; 7, Streptomyces sp. SD576; 8, S. sudanensis DSM41923 ; 9, S. sudanensis SD509; 10, S. sudanensis DSM41607; 11, S. sudanensis DSM41608; 12, S. sudanensis DSM41609; 13, S. somaliensis DSM40738 ; 14, Streptomyces sp. SD 511; 15, Streptomyces sp. SD534; 16, Streptomyces sp. SD528; 17, Streptomyces sp. SD524; 18,

Streptomyces sp. DSM40760.

their study [18]. The method was found suitable for testing strains of Streptomyces and other clinically significant aerobic actinomycetes. Application of genotypic and phenotypic analysis enables description of many novel species. These are in addition to S. somaliensis, the classic known cause of actinomycetoma in human. The slow and often filamentous growth of actinomycetes does not allow sufficient standardization of both the agar dilution and broth dilution method [13]. Knowledge on the antibiotic susceptibility of pathogenic actinomycetes is considered a challenge. This is why the chemotherapy of diseases caused by actinomycetes may still present problems. Complete and reliable data on the in vitro sensitivity of these pathogens can be obtained, however, when standardized and specially adapted methods of susceptibility testing are employed [19]. Special adaptations should cover the general technique of in vitro testing, as well as the choice of test media, the preparation of inocula, incubation methods and method of reading results. Provided that all factors are taken into account which might cause difficulties in test reproducibility and therapeutic relevance of the results, in vitro tests appear to contribute to the revision and updating of treatment regimes for many infections including human actinomycosis [19].

\section{Conclusions}

Streptomyces spp. from cases actinomycetoma in man and animals are phenotypically diverse and have wide range of susceptibility patterns to antimicrobial agents. This causes a lot of difficulties in selecting effective in vivo treatment for actinomycetoma in man and animals. Studies are underway in Sudan, UK, Poland and Mexico to complete the genotypic characterization of all 


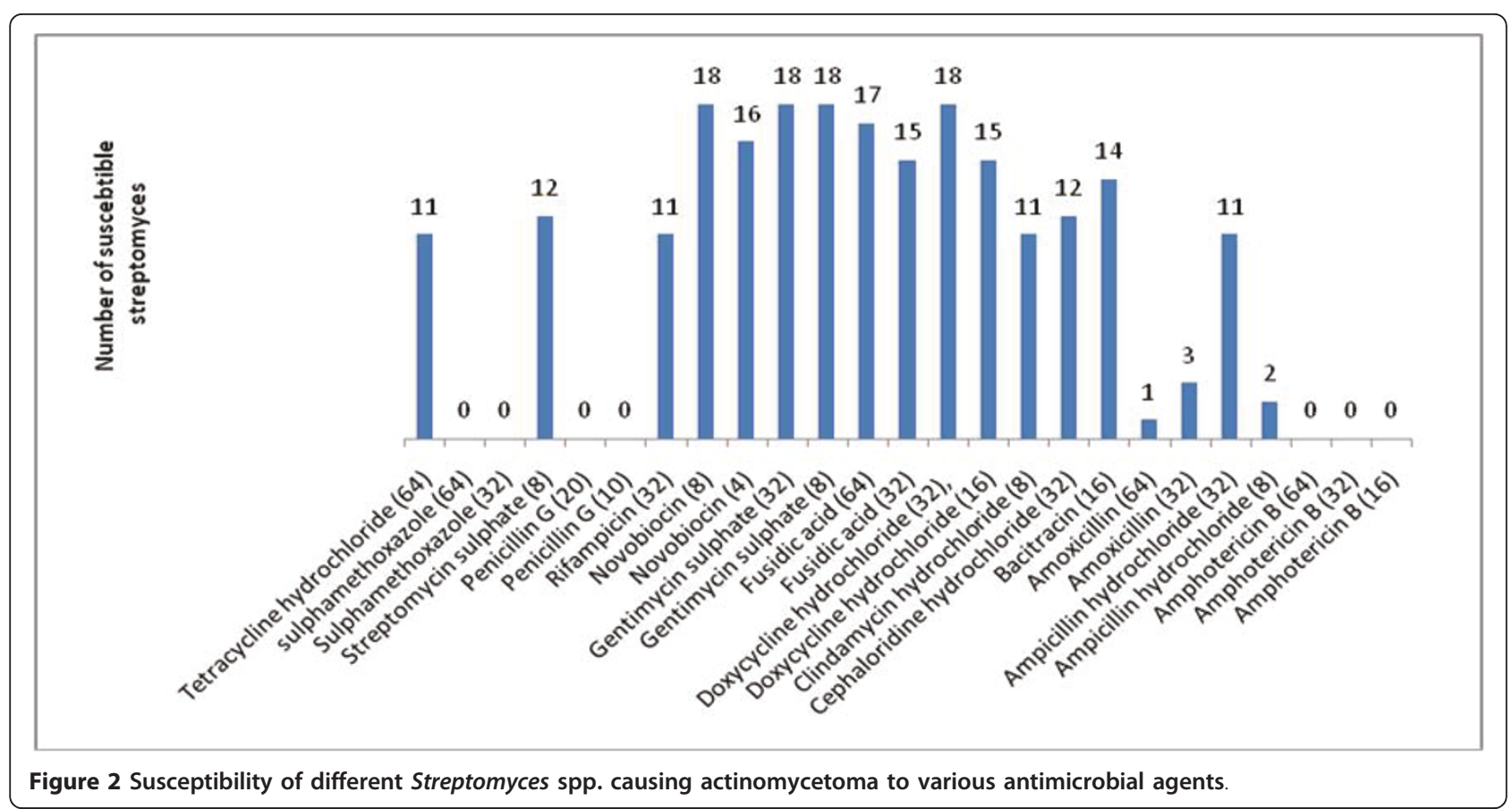

recognized phenotypes isolated from actinomycetoma cases in Sudan so far.

\section{Acknowledgements}

The author acknowledges: Prof. M Goodfellow (University of Newcastle); L Maldonado, E Quintana (Universidad Nacional Autónoma de México); Prof AH Fahal (University of Khartoum). Thank is extended to Mayami, Salma, Limia and Adil for their help during the research project. The project was supported by The British Council, Khartoum (KHT/991/21/Net).

\section{Authors' contributions}

The author has designed the study, perform the phenotypic characterization, susceptibility testing and have drafted the manuscript. Assistances during field collection of specimens and technical laboratory work are acknowledged in the acknowledgement section.

\section{Competing interests}

The author declares that he has no competing interests.

Received: 30 March 2011 Accepted: 6 June 2011 Published: 6 June 2011

\section{References}

1. Lichon V, Khachemoune A: Mycetoma: a review. Am J Clin Dermatol 2006 7:315-321.

2. Gumaa SA: The aetiology and epidemiology of mycetoma. Sudan Med J 1994, 32(Suppl):14-22.

3. Welsh O, Vera-Cabrera L, Salinas-Carmona MC: Mycetoma. Clin Dermatol 2007, 25:195-202.

4. Quintana ET, Wierzbicka K, Mackiewicz P, Osman A, Fahal AH, Hamid ME, Zakrzewska-Czerwinska J, Maldonado LA, Goodfellow M: Streptomyces sudanensis sp. nov., a new pathogen isolated from patients with actinomycetoma. Antonie Van Leeuwenhoek 2008, 93:305-313.

5. Mahgoub ES: Mycetoma. Int J Dermatol 1985, 24:230-239.

6. Fahal AH, Hassan MA: Mycetoma. Brit J Surg 1992, 79:1138-1141.

7. Fahal AH: Mycetoma: a thorn in the flesh. Trans R Soc Trop Med Hyg 2004, 98:3-11.

8. Fahal AH: Mycetoma: Clinicopathological Monograph. Khartoum: Khartoum University Press; 2006.
9. Ameen $M$, Arenas R: Emerging therapeutic regimes for the management of mycetomas. Expert Opin Pharmacoter 2008, 9:2077-2085.

10. Manfio GP, Zakrzewska-Czerwinska J, Atalan E, Goodfellow M: Towards minimal standards for the description of Streptomyces species. Biotechnologia 1995, 7-8:242-253.

11. Welsh O: Mycetoma. Current concepts in treatment. Int J Dermatol 1991, 30:387-398.

12. Elzein S, Hamid ME, Quintana E, Mahjoub A, Goodfellow M: Streptomyces sp., a cause of fistulous withers in donkeys. Dtsch Tierarztl Wochenschr 2002, 109:442-443.

13. Kämpfer P: The family Streptomycetceae. In The Prokaryotes. Volume 3.. 3 edition. Edited by: M Dworkin, E Rosenberg, K-H Schleifer, E Stackebrandt. Springer: NY; 2007, Archaea and Bacteria: Firmicutes, Actinomycetes.

14. National Committee for Clinical Laboratory Standards (NCCLS): Susceptibility testing of mycobacteria, nocardiae, and other aerobic actinomycetes; approved standard: NCCLS Document M24-A. Wayne, Pa; 2003.

15. Welsh $\mathrm{O}$, Salinas MC, Rodríguez MA: Treatment of eumycetoma and actinomycetoma. Curr Top Med Mycol 1995, 6:47-71.

16. Fahal AH: Mycetoma Management Guideline. Mycetoma Research Centre, Khartoum, Sudan;[http://mycetoma.uofk.edu/academic/updates_MMG.htm].

17. Nasher MA, Hay RJ, Mahgoub ES, Gumaa SA: In vitro studies of antibiotic sensitivities of Streptomyces somaliensis - a cause of human actinomycetoma. Trans R Soc Trop Med Hyg 1989, 83:265-268.

18. Kelly LM, Jacobs MR, Appelbaum PC: Comparison of agar dilution, microdilution, Etest and disc diffusion to test the activity of trovafloxacin against Pseudomonas aeruginosa, methicillin-resistant Staphylococcus aureus and Streptococcus pneumoniae. J Antimicrob Chemother 1999, 43:707-709.

19. Schaal KP, Pape W: Special methodological problems in antibiotic susceptibility testing of fermentative actinomycetes. Infection 1980, 8(Suppl- 2):S176-S182.

doi:10.1186/1476-0711-10-24

Cite this article as: Hamid: Variable antibiotic susceptibility patterns among Streptomyces species causing actinomycetoma in man and animals. Annals of Clinical Microbiology and Antimicrobials 2011 10:24. 